\title{
Low back and neck pain intensity and relationship with disability index among dentists
}

\author{
Nadri H, MSc ${ }^{1}$, Fasih Ramandi F, MSc ${ }^{2 *}$ \\ 1- MSc in Occupational Health Engineering, Dept. of Occupational Health, School of Public Health, Shahid Beheshti \\ University of Medical Sciences, Tehran, Iran. 2- MSc Student in Occupational Health Engineering, Dept of Occupational \\ Health, Student Research Committee, Shahid Beheshti University of Medical Sciences, Tehran, Iran.
}

\begin{abstract}
Received: January 2017, Accepted: March 2017

Background: Non-specific pain of low back and neck has direct impact on quality of life, active days at work, and health care costs. The purpose of this study was to determine the pain intensity and disability index for low back and neck among dentists.

Materials and Methods: This cross-sectional study was conducted among 80 dentists $(44.6 \%$ female and 55.4\% male). Dentists pain intensity and low back and neck disability index were evaluated with the self-administered visual analog scale and Oswestry questionnaire, respectively. Statistical data analysis was done using SPSS.

Results: Disability index of low back and neck has been reported equal to $26.6 \pm 10.7$ and $22.0 \pm 8.8$, respectively. Also the data showed the average pain intensity of low back and neck to be $75.5 \pm 24$ and $49.6 \pm 19.7$. The result showed significant relationship between pain intensity and disability index for low back and neck with body mass index (BMI) and exercise $(\mathrm{P}<0.05)$.

Conclusions: According to results, dentists have a high pain prevalence and moderate disability index of low back and neck. Also based on the relationship between the pain and disability index values with BMI and exercise, we recommend practice of relaxation and stretching exercises during breaks in the dentists work schedules to minimize the risk of work-related musculoskeletal disorders among dentists.
\end{abstract}

Keywords: Disability, Low Back Pain, Neck Pain, Pain

\section{Introduction}

Based on previous studies, the most important work-related musculoskeletal disorders among dentists have been reported in the back (80\%), neck (58.8\%) and shoulder (47\%) (1-6). According to several causes of low back pain (LBP), combined movements of bending by tilting the waist increases the risk of lumbar disc disease, on the other hand, the lack of flexibility and weakness of abdominal and gluteal muscles as the stabilizers of the lumbar spine will reinforce this risk (7). Anthropometric features such as height and body weight will increase lumbar lordosis (8), decrease abdominal muscle strength (9) and mobility in the lumbar spine (10). Finally, it will increase the risk of chronic LBP, so that Youdas et al. reported the risk of developing
LBP in women weighing more than $100 \mathrm{~kg}$ and in men with a height greater than $180 \mathrm{~cm}$. In addition, they found a significant relation between reduction of the abdominal muscles strength and LBP (11).

One of the most frequent complaints of patients with cervical spine disorders is neck pain and it is a common symptom in the general population (12-14). Neck pain is as common as LBP and it has caused almost the same number of days lost due to absence from work (15). It is estimated that a third of adults will experience neck pain during the one-year period (16) and about 19 percent of the

\footnotetext{
* Corresponding author: Fatemeh Fasih Ramandi, Dept of Occupational Health, Student Research Committee, Shahid Beheshti University of Medical Sciences, Tehran, Iran.

E-mail: f.fa30h@gmail.com
} 
population may suffer from chronic neck pain (17). In a study of body posture during work, it was shown that 86 percent of the time, dentists work with at least 30 degree-bent neck and 52 percent of the time, they work with at least 30 degree-bent body (18). The main reason for poor physical condition can be achieving the ideal view of the patient's mouth and providing a comfortable position for the patient (7).

Pain and limited movement of the spine has adverse effects in different styles on functional status, work activities and quality of life, so it is essential that researchers use tools having acceptable validity and reliability to review the inability level and determine the consequences $(19,20)$. Today, the definition of the World Health Organization (WHO) of the impairment, disability, and handicap is widely accepted (21). According to the studies on patients with back pain, disability index [Oswestry Disability Index (ODI)] is logically limited to WHO definition of disability (22, 23) because it is too difficult to measure disability through questionnaire (24).

Measuring disability is an important component in the management of patients with back and neck pain. Self-report questionnaire of Oswestry is stronger tool compared with , reporting the average value of syptom during last week by other tools, and is confirmed by American Academy of Orthopedic Surgeons (AAOS), and is a very important evaluation tool for researchers, measuring permanent functional inability (25).

In this study, the authors aimed to assess the prevalence and intensity of dentists LBP and neck pain in the first step. In the second step, they aimed to determine low back pain disability index (LBPDI) and neck disability index (NDI) among dentists in order to establish preventative measures for LBP and neck pain.

\section{Material and Methods}

This cross-sectional study was conducted among dentists of a specialized clinic affiliated with one of the universities of medical sciences in Tehran in 2016. All the employed dentists were enrolled in the study by census (80 dentists). All dentists had consented to participate in this study. The criteria for inclusion in the study were the lack of a history of spinal surgery and traumatic orthopedic problems such as acute neck and back and nerve problems, inflammatory diseases such as ankylosing spondylitis involving the spine, congenital diseases such as scoliosis and hemivertebrae. Due to the mentioned factors, 6 dentists were excluded from the study.

In the first phase, the prevalence and intensity of dentists LBP and neck pain was assessed by body map questionnaire with a visual analogue scale. In second phase, low back pain disability index (LBPDI) and neck disability index (NDI) among dentists was determined using ODI questionnaire (35 dentists with LBP and 43 dentists with neck pain). In the following, used questionnaires and tools are briefly introduced:

Body Map Questionnaire: To evaluate the prevalence of musculoskeletal disorders, body map questionnaire was used (26). Validity and reliability of the mentioned questionnaire was determined by Saremi, among Shahed university dentists (27) and it has been used in Nadri et al. study (6). In this questionnaire, to facilitate understanding and position of musculoskeletal disorders, body is divided into 13 areas including low back (LB), neck and etc. in form of a map (26).

Visual analog scale: Visual analog scale is made up of a horizontal line with a length of $100 \mathrm{~mm}$ and it has two labels including without discomfort and severe discomfort on both sides. To show the level of pain in different parts of body, the subject specifies a point on the line that indicates the level of pain felt by him or her. Then, the severity of discomfort is recorded numerally from zero to 100 using a millimeter ruler. Easy management, sensitivity and ability to respond to statistical analysis can be noted as benefits of visual analog scale (26). 
LLBP and Neck Disability Indices: A modified version of the ODI questionnaire has a high reliability and validity for the severity of the disability caused by neck pain and LBP $(25,28-31)$. The questionnaire consists 10 sections; including 7 sections on the activities of daily living, 2 sections for pain and 1 section associated with the focus. The questionnaire or index examines the degree of disability resulted from neck pain and its effect on daily activities of the person. In each section, the degree of disability in performance has been scored from zero (desirable performance and without pain) to five (disability in performance due to severe pain), and the total score is recorded in percentage. So that disability degree is interpreted as mild ( $0 \%$ to $20 \%$ ), moderate ( $21 \%$ to $40 \%$ ), severe (41\% to $60 \%)$, disabling (61\% to $80 \%)$ and severely disabling $(81 \%$ to $100 \%)(25,28)$.

Statistical data analysis was done using SPSS (version 22.0, IBM Corporation, Armonk, NY, USA). Kolmogorov-Smirnov test was used to determine the normality of the data. To examine the relationship between demographic characteristics (marital status, gender, and sport) with LBPDI and NDI, the chi-square test was used. to associate the relationship between pain intensity and disability with age, work experience and body mass index (BMI), due to the absence of parametric conditions, the Spearman correlation coefficient was used $(\mathrm{P}<0.05)$.

\section{Results}

About 44.6 percent (33 people) and 55.4 percent (41 people) of the subjects were female and male, respectively. According to the classification of BMI by health communities (33), $4 \%$ of the patients in this study were classified as underweight, $41.9 \%$ normal, $47.3 \%$ as overweight and only 6.8 percent were obese. Therefore, the highest frequency of BMI of people in the study belonged to the overweight class. Table 1 shows the demographic characteristics of the subjects.

Table 1: Distribution of dentists' demographic characteristics

\begin{tabular}{lcc}
\hline Variables & Mean \pm SD & Range \\
\hline Age (year) & $38.2 \pm 6.6$ & $26-53$ \\
\hline Experience (year) & $12.7 \pm 7.1$ & $2-32$ \\
\hline Height $(\mathrm{cm})$ & $171.9 \pm 8.7$ & $155-190$ \\
\hline Weight $(\mathrm{kg})$ & $74.5 \pm 15.9$ & $42-120$ \\
\hline BMI $\left(\mathrm{kg} \mathrm{m}^{-2}\right)$ & $25.8 \pm 4.3$ & $16.8-35.1$ \\
\hline
\end{tabular}

SD: Standard deviation; BMI: Body mass index

There was no significant difference in the relationship between the prevalence of LBP and neck pain with sex, marital status and work habits (left or right handed) ( $\mathrm{P}>0.05$ ). Results of prevalence and classification of
LBP and neck pain are shown in table 2. LBP in $40 \%$ of patients was classified as severely disabling. In addition, severe neck pain had had the highest percentage $(46.5 \%)$.

Table 2: Percent distribution of low back and neck pain intensity among dentists

\begin{tabular}{cccccccc}
\hline \multirow{2}{*}{$\begin{array}{c}\text { Pain } \\
\text { intensity }\end{array}$} & Prevalence & \multirow{2}{*}{$\begin{array}{c}\text { Mean } \\
(\text { SD })\end{array}$} & $\begin{array}{c}\text { Mild } \\
(\mathbf{0 - 2 0})\end{array}$ & $\begin{array}{c}\text { Moderate } \\
(\mathbf{2 1 - 4 0})\end{array}$ & $\begin{array}{c}\text { Severe } \\
(\mathbf{4 1 - 6 0})\end{array}$ & $\begin{array}{c}\text { Disabling } \\
(\mathbf{6 1 - 8 0})\end{array}$ & $\begin{array}{c}\text { Severe disabling } \\
(\mathbf{8 1 - 1 0 0})\end{array}$ \\
\hline Low Back & $\mathbf{4 7 . 3}$ & $\mathbf{7 5 . 5} \pm \mathbf{2 4}$ & - & $\mathbf{1 1 . 4}$ & $\mathbf{2 5 . 7}$ & $\mathbf{2 2 . 9}$ & 40 \\
\hline Neck & $\mathbf{5 8 . 1}$ & $\begin{array}{c}49.6 \pm \\
19.7\end{array}$ & 4.7 & 27.9 & 46.5 & 9.3 & 11.6 \\
\hline
\end{tabular}

SD: Standard deviation 
Table 3: Percent distribution of disability index of low back and neck among dentists

\begin{tabular}{ccccccc}
\hline \multirow{2}{*}{$\begin{array}{c}\text { Disability } \\
\text { index }\end{array}$} & Mean (SD) & \multicolumn{5}{c}{ Disability index (\%) } \\
\cline { 3 - 7 } & $\begin{array}{c}\text { Mild } \\
(\mathbf{0 - 2 0})\end{array}$ & $\begin{array}{c}\text { Moderate } \\
(\mathbf{2 1 - 4 0 )}\end{array}$ & $\begin{array}{c}\text { Severe } \\
(\mathbf{4 1 - 6 0 )}\end{array}$ & $\begin{array}{c}\text { Disabling } \\
(61-80)\end{array}$ & $\begin{array}{c}\text { Severe disabling } \\
(\mathbf{8 1 - 1 0 0 )}\end{array}$ \\
\hline Low back & $\mathbf{2 6 . 6 \pm 1 0 . 7}$ & $\mathbf{3 4 . 3}$ & $\mathbf{6 0}$ & 5.7 & - & - \\
\hline Neck & $\mathbf{2 2} \pm \mathbf{8 . 8}$ & $\mathbf{5 3 . 5}$ & $\mathbf{4 4 . 2}$ & $\mathbf{2 . 3}$ & - & - \\
\hline
\end{tabular}

SD: Standard deviation

Results of LBPDI and NDI and its classification are shown in table 3. LBPDI of $60 \%$ dentists was in the moderate class and NDI of $53.5 \%$ dentists was in mild class.

Results of the relationship between disability index and LB and neck pain intensity and the variables of marital status, gender, age, work experience, exercise and BMI are shown in table 4. The disability index of neck pain, disability index of LBP, neck pain intensity and LBP intensity had a significant relationship with BMI and exercise.

Table 4: Relationship between intensity pain and disability index of low back and neck with dentists' demographic characteristics

\begin{tabular}{ccccccc}
\hline Variables & $\begin{array}{c}\text { Married } \\
\text { (P-value) }\end{array}$ & $\begin{array}{c}\text { Gender } \\
\text { (P-value) }\end{array}$ & $\begin{array}{c}\text { Age } \\
\text { (P-value) }\end{array}$ & $\begin{array}{c}\text { Experience } \\
\text { (P-value) }\end{array}$ & $\begin{array}{c}\text { Exercise } \\
\text { (P-value) }\end{array}$ & $\begin{array}{c}\text { BMI } \\
\text { (P-value) }\end{array}$ \\
\hline $\begin{array}{c}\text { Low back pain } \\
\text { disability index }\end{array}$ & 0.597 & 0.260 & 0.481 & 0.643 & 0.034 & 0.003 \\
\hline $\begin{array}{c}\text { Low back pain } \\
\text { intensity }\end{array}$ & 0.075 & 0.058 & 0.552 & 0.885 & 0.014 & 0.006 \\
\hline $\begin{array}{c}\text { Neck disability } \\
\text { index }\end{array}$ & 0.947 & 0.751 & 0.985 & 0.357 & 0.002 & 0.002 \\
\hline Neck pain intensity & 0.238 & 0.430 & 0.857 & 0.750 & 0.064 & 0.003 \\
\hline
\end{tabular}

BMI: Body mass index

\section{Discussion}

Oswestry Pain Questionnaire evaluates the effects of pain on performance and how to do everyday activities. In other words, it examines the psychological status of a person's beliefs and attitudes of his inability to perform everyday activities. Although the efficacy of the disability questionnaires to evaluate disability has been reported in many studies $(25,32)$, the results of this evaluation method can be influenced by the person's attitude towards the effect of pain on his life. However, disability evaluation questionnaires show an important aspect of limitation in performance that this issue represents the significance of using them especially in the first referral to occupational therapists, because the patient provides a general image of his performance for the occupational therapist in addition to his belief about pain and disability (33).

According to the studies measuring the intensity of pain, visual analog scale flaws can be confusing when showing pain intensity on one line, and its correct understanding by the test subjects, so that elderly and illiterate people will have the highest problem here. Given that the target population in this study were all educated, by confidence, it can be stated that such a problem would not be an issue $(6,26)$.

In the present study, disability of LBP and neck pain mean has been reported as $26.6 \pm$ 10.7 and $22 \pm 8.8$, respectively. The index of disability resulted from LBP in $60 \%$ of people of the study was placed in the classification of average disability index (with the range of 21 to 40 ). In addition, $53.5 \%$ and $44.2 \%$ of people had mild and moderate disability index resulted from neck pain, respectively. According to interpretation of moderate disability index, although personal care and sleep in these patients are not affected greatly, they have more pain when sitting, standing and lifting, traveling and social life are difficult for 
them, and it might lead to missing their work. Pain is the main problem of this group and affects their daily activities. Therefore, it needs more detailed investigation. In the study of Ilyas and Dharmaji (34), $74.4 \%$ and $25.6 \%$ of the studied dentists had mild to moderate disability index resulted from LBP (36). Gaowgzeh et al. reported $70 \%$ prevalence of LBP among dentists, and $90.5 \%$ of the subjects had mild to moderate intensity level and $9.5 \%$ had severe (35). In addition to reporting 39.4 percent of neck pain prevalence, Eftekhar Sadat et al. reported the mean of NDI in medical students equal to $14.6 \pm 9.7$ (mild disability) (36). Moreover, Carreon et al., reported NDI among patients with neck pain equal to $26.5 \pm 8.7$ (37).

Since studying the amount of pain in addition to the prevalence, a useful tool is to evaluate the effectiveness of ergonomic interventions in the form of before and after study (26). In this study, the prevalence of neck pain and LBP among subjects was reported as $58.1 \%$ and $47.3 \%$ respectively, as well as LBP and neck pain intensity evaluated by visual analog scale was equal to $75.5 \%$ and $49.6 \%$, respectively. In addition, among dentists with neck pain, $46.5 \%$ of them were placed in the severe pain class. The results on prevalence and the intensity of pain in the neck and LB areas in the present study are in line with the results of Nadri et al. study (6). In unbalanced forward postures of neck and head to achieve better visibility, vertebrae cannot support the spine for a long time. As a result, neck and upper thoracic spine muscles must be continually contracting to support the weight of the head in forward posture (38). This condition leads to pain patterns and will be characterized as neck tension syndrome with headache and chronic pain in the neck, shoulders, and muscles of the shoulder. So that maintaining contraction of neck muscles will cause weakening and degeneration or herniation of spinal discs (39). Moreover, the results of other studies have reported bending and raising neck, as well as removing shoulder from the body axis and high activity of arm as the reasons of neck and shoulder pain (40-42). More than 80 percent of dentists complain of back and upper body pain, which is the direct result of posture and movements of dentists in their daily work (43). In a sitting position, lumbar arc drops and prevents LBP (44). It is better for dentists to change their working positions according to the involving muscle group as much as possible (45). Changing the sitting and standing positions can be an effective strategy since those dentists who were working only in the sitting position had more LBP than those with rotating standing and sitting position (46). In this study, a significant difference was found in the incidence of LBP and neck pain associated with daily exercise. Therefore, NDI, LBPDI, LBP and neck pain intensity were higher in the non-exercising dentists. It can be stated that despite pain is multi factorial, it seems that by strengthening the muscles of the shoulder girdle and neck, straightening muscles of the spine and abdominal muscles and increasing muscle power, the pressure on discs and spinal joints will decrease. At the end, it leads to reduction of pain and prevents the incidence of this complication in these dentists. Results of various studies have shown the effect of different exercises on reduction of the pain (47, 48). Nevertheless, the results of some studies do not match with our findings (36, 49).

In the present study, NDI, LBPDI, LBP and neck pain intensity had a significant relationship with BMI, and dentists with higher disability index and pain intensity had a higher BMI. This finding is aligned with the results of Eftekhar Sadat et al. (36) and Youdas et al. studies, that reported higher risk of developing LBP in women weighing more than $100 \mathrm{~kg}$ and in men with a height greater than $180 \mathrm{~cm}$ (11). In addition, Makela et al., reported high weight as an important factor in neck pain (50). In another study, a higher prevalence of neck pain had been reported in people with a BMI less than 15 (51). However, in the present study, a significant statistical 
relation was not reported between neck pain and LBP intensity with variables such as sex, age, and work experience, that is aligned with the results of many other studies $(5,6,51,52)$.

\section{Conclusion}

The results of the present study suggest a high prevalence of neck pain and LBP among studied dentists. The results of studying pain intensity and disability caused by neck pain and LBP indicated that more attention is required towards improving working conditions for dentists using long-term training courses to become familiar with ergonomics, using ergonomic equipment adapted to anthropometric dimensions of users, involvement in sports and appropriate corrective action programs in the workplace, planning and management of work and rest schedules, and even inclusion of these issues in the form of training courses. The small sample size and the study conduction in one dentistry clinic were the limitations of this study, therefore it is better to conduct similar studies in large and different populations.

\section{Acknowledgment}

This study is related to the project NO. 1395/47796 from Student Research Committee, Shahid Beheshti University of Medical Sciences, Tehran, Iran. We also appreciate the "Student Research Committee" and "Research and Technology Chancellor" in Shahid Beheshti University of Medical Sciences for their financial support of this study.

Conflict of interest: None declared

\section{References}

1. Morse $\mathrm{T}$, Bruneau H, Michalak-Turcotte C, Sanders M, Warren N, Dussetschleger J, et al. Musculoskeletal disorders of the neck and shoulder in dental hygienists and dental hygiene students. J Dent Hyg 2007; 81(1):1-16.
2. Shrestha BP, Singh GK, Niraula SR. Work related complaints among dentists. J Nepal Med Assoc 2008; 47(170):77-81.

3. Hayes M, Cockrell D, Smith DR. A systematic review of musculoskeletal disorders among dental professionals. Int J Dent Hyg 2009; 7(3):159-65.

4. Hayes MJ, Smith DR, Cockrell D. Prevalence and correlates of musculoskeletal disorders among Australian dental hygiene students. Int J Dent Hyg 2009; 7(3):176-81.

5. Ahmadi Motemayel F, Abdolsamadi H, Roshanaei Gh, Jalilian S. Prevalence of musculoskeletal disorders among hamadan general dental practitioners. Scientific Journal of Hamadan University of Medical Sciences 2012; 19(3):61-6.

6. Nadri H, Nadri A, Rohani B, Fasih Ramandi F, Aminsobhani M, Naseh I. Assessment of musculoskeletal disorders prevalence and body discomfort among dentists by visual analog discomfort scale. Journal of Mashhad Dental School 2015; 39(4):363-72.

7. Gupta A, Bhat M, Mohammed T, Bansal N, Gupta G. Ergonomics in dentistry. Int J Clin Pediatr Dent 2014; 7(1):30-4.

8. Claus AP, Hides JA, Moseley GL, Hodges PW. Is 'ideal' sitting posture real? measurement of spinal curves in four sitting postures. Man Ther 2009; 14(4):404-8.

9. Lee SH, Kim TH, Lee BH. The effect of abdominal bracing in combination with low extremity movements on changes in thickness of abdominal muscles and lumbar strength for low back pain. J Phys Ther Sci 2014; 26(1):157-60.

10. Phillips FM, Slosar PJ, Youssef JA, Andersson G, Papatheofanis F. Lumbar spine fusion for chronic low back pain due to degenerative disc disease: a systematic review. Spine 2013; 38(7):E409-22.

11. Youdas JW, Garrett TR, Egan KS, Therneau TM. Lumbar lordosis and pelvic inclination in adults with chronic low back pain. Phys Ther 2000; 80(3):261-75.

12. Kennedy J, Roll JM, Schraudner T, Murphy S, McPherson S. Prevalence of persistent pain in the U.S. adult population: new data from the 2010 national health interview survey. J Pain 2014; 15(10):979-84.

13. Vasseljen O, Woodhouse A, Bjørngaard JH, Leivseth L. Natural course of acute neck and low back pain in the general population: the HUNT study. Pain 2013; 154(8):1237-44.

14. Nachemson AL, Jonsson E. Neck and back pain: the scientific evidence of causes, diagnosis, and treatment. Philadelphia, United States: Lippincott Williams and Wilkins; 2000. 
15. Hansson T, Jensen I. Swedish council on technology assessment in health care (SBU). Chapter 6. Sickness absence due to back and neck disorders. Scand J Public Health Suppl 2004; 63:109-51.

16. Rose T, Butler J, Salinas N, Stolfus R, Wheatley T, Schenk R. Measurement of outcomes for patients with centralising versus non-centralising neck pain. J Man Manip Ther 2016: 24(5):264-8.

17. Gross AR, Paquin JP, Dupont G, Blanchette S, Lalonde $\mathrm{P}$, Cristie $\mathrm{T}$, et al. Exercises for mechanical neck disorders: a cochrane review update. Man Ther 2016; 24:25-45.

18. Marklin RW, Cherney K. Working postures of dentists and dental hygienists. J Calif Dent Assoc 2005; 33(2):133-6.

19. Bombardier C. Outcome assessments in the evaluation of treatment of spinal disorders: summary and general recommendations. Spine 2000; 25(24):3100-3.

20. Jackowski D, Guyatt G. A guide to health measurement. Clin Orthop Relat Res 2003; (413):80-9.

21. Simeonsson RJ, Lollar D, Hollowell J, Adams M. Revision of the international classification of impairments, disabilities, and handicaps: developmental issues. J Clin Epidemiol 2000; 53(2):113-24.

22. Ostelo RW, de Vet HC. Clinically important outcomes in low back pain. Best Pract Res Clin Rheumatol 2005; 19(4):593-607.

23. Bucknill TM. Outcome measures in orthopaedics. British Medical Journal 1993 Aug 7; 307(6900):393.

24. Raspe H. A database for back (axial skeletal) pain. Rheum Dis Clin North Am 1995; 21(2):559-79.

25. Fairbank JC, Pynsent PB. The oswestry disability index. Spine 2000; 25(22):2940-52.

26. Straker LM. Body discomfort assessment tools. In: Karwowski W, Marras W. Occupational ergonomics: engineering and administrative controls. 1st ed. Boca Raton, Florida, United States: CRC Press; 2003. P.1-26.

27. Saremi M. Assessment of musculoskeletal disorders among dentistry of Shahed University, using REBA method and provide appropriate corrective methods [MSc thesis]. Tehran: Tarbiat Modarres University; 2003.

28. Fairbank JC, Couper J, Davies JB, O'brien JP. The oswestry low back pain disability questionnaire. Physiotherapy 1980; 66(8):2713.

29. Vernon H, Mior S. The Neck Disability Index: a study of reliability and validity. J Manipulative Physiol Ther 1991; 14(7):409-15.
30. Mousavi SJ, Parnianpour M, Montazeri A, Mehdian H, Karimi A, Abedi M, et al. Translation and validation study of the Iranian versions of the Neck Disability Index and the Neck Pain and Disability Scale. Spine 2007; 32(26):E825-31.

31. MacDermid JC, Walton DM, Avery S, Blanchard A, Etruw E, McAlpine C, et al. Measurement properties of the neck disability index: a systematic review. J Orthop Sports Phys Ther 2009; 39(5):400-17.

32. Roland M, Fairbank J. The roland-morris disability questionnaire and the oswestry disability questionnaire. Spine 2000; 25(24):3115-24.

33. Reneman MF, Jorritsma W, Schellekens JM, Göeken LN. Concurrent validity of questionnaire and performance-based disability measurements in patients with chronic nonspecific low back pain. J Occup Rehabil 2002; 12(3):119-29.

34. Ilyas M, Dharmaji TP. Low back pain in Dentists of Indonesia. Pakistan Oral \& Dental Journal 2012; 32(3):464-8.

35. Gaowgzeh RA, Chevidikunnan MF, Al Saif A, El-Gendy S, Karrouf G, Al Senany S. Prevalence of and risk factors for low back pain among dentists. J Phys Ther Sci 2015; 27(9):2803-6.

36. Eftekhar Sadat B, Babaei-Ghazani A, Azizi R, Parizad M. Prevalence and risk factors of neck and shoulder pain in medical students of Tabriz University of Medical Sciences. Medical Journal of Tabriz University of Medical Sciences and Health Services 2013; 35(3):12-7.

37. Carreon LY, Glassman SD, Campbell MJ, Anderson PA. Neck disability index, short form-36 physical component summary, and pain scales for neck and arm pain: the minimum clinically important difference and substantial clinical benefit after cervical spine fusion. Spine J 2010; 10(6):469-74.

38. Hertling D, Kessler RM. Management of common musculoskeletal disorders: physical therapy principles and methods. 1st ed. Philadelphia, United States: Lippincott Williams and Wilkins; 2006.

39. Linton SJ. A review of psychological risk factors in back and neck pain. Spine 2000; 25(9):1148-56.

40. Åkesson I, Balogh I, Hansson GÅ. Physical workload in neck, shoulders and wrists/hands in dental hygienists during a work-day. Appl Ergon 2012; 43(4):803-11.

41. Finsen L, Christensen H, Bakke M. Musculoskeletal disorders among dentists and variation in dental work. Appl Ergon 1998; 29(2):119-25. 
42. Lalumandier JA, McPhee SD, Parrott CB, Vendemia M. Musculoskeletal pain: prevalence, prevention, and differences among dental office personnel. Gen Dent 2000; 49(2):160-6.

43. Nield-Gehrig JS. Fundamentals of periodontal instrumentation \& advanced root instrumentation. 1st ed. Philadelphia, United States: Lippincott Williams and Wilkins; 2008.

44. Harrison DD, Harrison SO, Croft AC, Harrison DE, Troyanovich SJ. Sitting biomechanics part I: review of the literature. J Manipulative Physiol Ther 1999; 22(9):594-609.

45. Callaghan JP, McGILL SM. Low back joint loading and kinematics during standing and unsupported sitting. Ergonomics 2001; 44(3):280-94.

46. Ratzon NZ, Yaros T, Mizlik A, Kanner T. Musculoskeletal symptoms among dentists in relation to work posture. Work 2000; 15(3):153-8.

47. O'Sullivan PB, Mitchell T, Bulich P, Waller R, Holte J. The relationship beween posture and back muscle endurance in industrial workers with flexion-related low back pain. Man Ther 2006; 11(4):264-71.

48. Farahpour N, Marvi Esfahani M. Postural deviations from chronic low back pain and correction through exercise therapy. Tehran Univesity Medical Journal 2007; 65(2):69-77.

49. Waling K, Järvholm B, Sundelin G. Effects of training on female trapezius Myalgia: An intervention study with a 3-year follow-up period. Spine 2002; 27(8):789-96.

50. Fejer R, Kyvik KO, Hartvigsen J. The prevalence of neck pain in the world population: a systematic critical review of the literature. Eur Spine J 2006; 15(6):834-48.

51. Marshall SJ, Gorely T, Biddle SJ. A descriptive epidemiology of screen-based media use in youth: a review and critique. $\mathrm{J}$ Adolesc 2006; 29(3):333-49.

52. Yip VY. New low back pain in nurses: work activities, work stress and sedentary lifestyle. J Adv Nurs 2004; 46(4):430-40. 